\title{
CAP AL CEL OBERT (2000) DE CARME RIERA: HERMENĖUTICA I NARRATOLOGIA FEMINISTES
}

\author{
FRANCESCA BARTRINA
}

Universitat de Vic

\begin{abstract}
Aquest article ofereix una lectura de la novel-la Cap al cel obert (2000), de Carme Riera, a través de les eines metodològiques de les teories feministes sobre el plaer de la lectura. El primer focus d'anàlisi seran els conceptes d'"afinitat" i "tràfic de dones" desenvolupats per Gayle Rubin i la seva rellevància en la definició dels personatges femenins. A continuació, el pensament de Diana Fuss i Nancy Miller guiaran l'anàlisi de l'argument de David S. Parker, un argument que està fora de la trama principal de la novellla. Les obres de Susan Lanser i Susan Winnet ajudaran a posar de manifest la importància de l'epíleg, que no és de cap de les maneres prescindible, i el fet que la novel-la conclou "més enllà del final", en paraules de Rachel Blau DuPlessis. Aquesta història sense fi dóna a Maria, el personatge principal, la capacitat de sobreviure i convertir-se en una llegenda en la memòria col-lectiva.
\end{abstract}

Paraules ClaU: Carme Riera, Cap al cel obert, identitat i gènere, hermenèutica, postcolonialisme.

\section{Cap al cel obert (2000) de Carme Riera: Hermenéutica y narratología feminista}

Este artículo ofrece una lectura de la novela Cap al cel obert (2000), de Carme Riera, a través de las herramientas metodológicas de las teorías feministas sobre el placer de la lectura. El primer foco de análisis serán los conceptos de "afinidad" y "tráfico de mujeres" desarrollados por Gayle Rubin y su relevancia en la definición de los personajes femeninos. A continuación, el pensamiento de Diana Fuss y Nancy Miller guiarán el análisis del argumento de David S. Parker, un argumento que está fuera de la trama principal de la novela. Las obras de Susan Lanser y Susan Winnet ayudarán a poner de manifiesto la importancia del epílogo, que no es en modo alguno prescindible, y el hecho de que la novela concluye "más allá del final", en palabras de Rachel Blau DuPlessis. Esa historia sin fin da a Maria, el personaje principal, la capacidad de sobrevivir y convertirse en una leyenda en la memoria colectiva.

PALABRAS ClAVE: Carme Riera, Cap al cel obert, identidad y género, hermenéutica, poscolonialismo.

\section{Cap al cel obert (2000) by Carme Riera: Hermeneutics and Feminist Narratology}

In this article, the novel Cap al cel obert (2000) written by Carme Riera is read by the methodological tools of feminist theories on the pleasure of reading. The first focus of attention will be the concepts of "kinship" and "traffic of women" developed by Gayle Rubin and their relevance in defining female characters. After that, the thoughts of Diana Fuss and Nancy

Bartrina, Francesca (2013), "Cap al cel obert (2000) de Carme Riera: hermenèutica i narratologia feministes", Lectora, 19: 25-34. ISSN: 1136-5781 D.O.I.: XXXXXXXXX.

Recepció: 1 de juny 2012 - Acceptació: 30 de desembre 2012 
Miller will lead the analysis of the plot of David S. Parker, a plot that is outside of the main story of the novel. The works of Susan Lanser and Susan Winnett will help to reflect on the importance of the epilogue, which is not in any way expendable, and the fact that the novel ends "beyond the ending", to put it in Rachel Blau DuPlessis terms. That never ending story gives to Maria, the main character, the ability to survive and become a legend in the collective memory.

KEY WORDS: Carme Riera, Cap al cel obert, identity and gender, hermeneutics, postcolonialism.

Carme Riera va publicar Cap al cel obert sis anys després del pas de rosca que suposa en la seva narrativa Dins el darrer blau (1994) i quatre anys abans que $\mathrm{La}$ meitat de l'ànima (2004). D'aquesta manera, va dibuixar en la seva trajectòria un cicle de deu anys caracteritzat per una escriptura centrada en la recuperació de la memòria històrica $\mathrm{i}$ que es materialitza amb una àmplia polifonia de veus i de punts de vista narratius (Cotoner, 2005: 21). Així, Cap al cel obert ofereix totes les característiques de l'estil rierià: ús del gènere epistolar; ${ }^{1}$ acurada documentació històrica; presència de fets reals molt ben literaturitzats; ús de la ironia; riquesa lingüística i un final obert que li permet "escriure més enllà del final de la novel-la” per dir-ho en paraules de Rachel Blau DuPlessis i parafrasejant el títol del seu llibre Writing beyond the Ending (1985).

El punt de partida de la novel.la és la recerca històrica efectuada per Carme Riera entorn de la figura de Ramon Pintó, fundador del Liceo Artístico y Literario de l'Havana acusat de secessionisme i executat l'any 1854, malgrat la seva amistat amb el Capità General de Cuba, José Gutiérrez de la Concha. ${ }^{2}$ Àlex Broch (2004: 67) ha cridat l'atenció sobre la importància en la novel.la de les relacions entre Catalunya i Cuba i la denúncia de la corrupció política colonial. Però aquest punt de partida històric és apropiat per la imaginació rieriana $\mathrm{i}$ traslladat a l'univers de la seva ficció: són precisament els descendents dels protagonistes de Dins el darrer blau els que han fet fortuna a la Cuba colonial mitjançant el comerç d'esclaus negres; i han passat de ser víctimes a ser botxins, de ser perseguits i cremats a la foguera a ser esclavistes. Així, l'acció de Cap al cel obert transcorre entre 1850 i 1860 quan un matrimoni per poders aconsegueix el retrobament de dues branques de la mateixa família: els Fortesa de Mallorca i els Fortalesa de Cuba, tots dos descendents d'una de les protagonistes de Dins el darrer blau, Isabel Tarongí. I el model literari triat per tractar un fets que es situen en el segle XIX és justament la novel-la de fulletó. ${ }^{3}$

\footnotetext{
${ }^{1}$ L'ús del gènere epistolar en la novel-la ha estat estudiat per Bartrina (2011: 66-70).

${ }^{2}$ Tal com ha assenyalat Emilio Ramón, la novel-la parteix d'aquest fet per explicar-ne d'altres que no han estat mai explicats: "Por el cielo y más allá constituye un ejemplo de metaficción historiográfica que indaga en el pasado para poder así recuperar una serie de espacios alternativos que la historia oficial había pretendido borrar" (Ramón, 2005: 320).

${ }^{3}$ Sobre la pertinència del fulletó, vegeu les declaracions de l’autora a Pinyol (2000).
} 
En aquest article aplicarem les eines metodològiques de la teoria feminista per centrar l'atenció en el fet que les protagonistes femenines apareixen definides pels conceptes de parentiu i de tràfic de dones desenvolupats per Gayle Rubin. I per analitzar una trama que es troba al marge de la història principal de la novel.la: la de David S. Parker/Tomeu Moner. També reflexionarem sobre la importància de l'epíleg, que no és de cap manera prescindible, i del fet que la novel.la acabi "més enllà del seu final". La nostra intenció és proposar una via hermenèutica d'interpretació de la novel-la que es centri justament en aquests tres eixos: la impossibilitat dels personatges femenins de fugir de les relacions de parentiu i de tràfic, la importància de la trama de Parker i un final obert que atorga a la protagonista la possibilitat d'esdevenir llegenda i de perdurar en la memòria collectiva.

\section{Parentiu i tràfic de dones: de Maria Fortesa de Fortalesa a Violeta}

Cap al cel obert posa sobre la taula qüestions fonamentals entorn de la identitat jueva i de la identitat negra. ${ }^{4}$ D'una banda, la primera persegueix els personatges: Maria té problemes per ingressar en un convent pels seus orígens conversos; el senyor de Fortalesa ha de canviar el seu cognom i comprar un títol nobiliari per esborrar la seva nissaga i quan Maria és condemnada a mort, s'esgrimeix la qüestió jueva. De l'altra, Rosalía Cornejo Parriego ha estudiat el paper de la identitat negra a la novel.la i subratlla que "Por el cielo y más allá capta claramente ese temor palpable a la africanización de Cuba, que algunos sectores consideraban incompatible con su proyecto de nación" (Cornejo Parriego, 2011: 7). Aquesta estudiosa destaca que la bretxa que separa la dona blanca de la comunitat negra es totalment infranquejable: "El papel narrativo de María nos remite, de forma inevitable, a la doble posición de la mujer blanca en el mundo colonial donde, dada la intersección de los discursos coloniales y de género, ocupa simultáneamente el centro y la periferia" (Cornejo Parriego, 2011: 11).

Efectivament, aquest és el paper de Maria, un personatge que es troba totalment definit per les seves relacions de parentiu i pels efectes del tràfic de dones. Devem aquests dos conceptes a l'antropòloga nord-americana Gayle Rubin que els va elaborar a partir de la definició del sistema sexe-gènere, que va realitzar partint de l'obra de Lévi-Strauss i amb una perspectiva marxista i feminista. En les seves paraules:

El "intercambio de mujeres" no es ni una definición de la cultura ni un sistema en y por sí mismo. El concepto es una aprehensión aguda, pero condensada, de algunos aspectos de las relaciones sociales de sexo y

\footnotetext{
${ }^{4}$ Per un estudi de les narratives d'identitat de la novel.la vegeu Bartrina (2011).
} 
género. Un sistema de parentesco es una imposición de fines sociales sobre una parte del mundo natural. (Rubin, 1998: 35)

És per això que Maria passa de la tutela del seu pare, Josep Fortesa, a la tutela del seu marit i cosí del pare, Josep Joaquim de Fortalesa. La mort del progenitor fa que els seus germans l'obliguin a acompanyar a Cuba la seva germana Isabel, que s'ha casat per poders amb un cosí seu. A Cuba, Maria esdevé un element clau en la xarxa de relacions de parentiu ja que és el receptacle dipositari de la memòria de la família; això és així perquè el seu pare, abans de morir, l'ha convertida en la dipositària de seva memòria:

El vell, estimulat per les deferents orelles de la filla, l'anà fent dipositària de l'únic que era veritablement seu, i que només a ella semblava disposat a donar: la seva memòria. Durant els mesos previs a la celebració de les noces d'Isabel parlaren més del que no ho havien fet en tota la seva vida. Josep Fortesa solia menar la conversa cap a les zones que més podien interessar a la filla. (Riera, 2000: 33)

Tota la informació que ella rebrà en aquestes converses sobre el passat de la família serà un catalitzador important que seduirà el senyor de Fortalesa quan visqui acollida a casa seva sense saber quin serà el seu destí: "Passaren molts de capvespres asseguts encara a la taula sense que els esclaus poguessin treure les estovalles, tot i que gairebé ja era hora de servir el sopar, entretinguts en una conversa inacabable al recer de la memòria fidelíssima de Maria" (Riera, 2000: 134). Per tant, serà el paper que ocupa Maria com a guardiana de la memòria familiar allò que justifica les seves relacions de parentiu i allò que enamorarà el senyor la Fortalesa, quaranta anys més gran que no pas ella.

Tanmateix, Maria no serà capaç d'ajudar una víctima evident del tràfic de dones, l'esclava negra Felicitas, de la mateixa manera que tampoc el personatge d'Àngela ho serà d'ajudar l'esclava blanca Violeta. Aquests són dos casos paral.lels, com molt bé va explicar Fermando Valls (2000: 303-304). Felicitas és la jove esclava negra que cuida Maria i li explica els abusos a què la sotmet Miquel, de la mateixa manera que el senyor de Fortalesa havia abusat de la seva mare. Violeta és l'esclava blanca que Àngela descobreix a la finca de Parker; més tard, ell mateix li explica que es dedica al tràfic sexual de nenes amb la seva sòcia Dorothy. Àngela, que si bé assumeix el discurs racista amb tota naturalitat quan es tracta d'esclavatge de negres, s'escandalitza davant l'existència d'esclavatge de blancs. Considero que aquest és un element central de la novel.la. Segueixo Diane Fuss (1989) quan explica que no hi ha cap lectura "natural": totes les lectures són històricament i culturalment variables, i les posicions lectores són sempre construïdes o assignades. D’aquesta manera, sota la llum de la classificació de Rubin que hem vist més amunt, podem llegir Cap al cel obert com una novel.la 
en la qual el tràfic de dones és un element fonamental per entendre tota la xarxa de relacions que s'entrellacen.

Fuss, que parteix de la teoria de la subjectivitat de Lacan, entén el procés de lectura com un espai que permet tractar diferents negociacions i on la lectora pot ocupar diverses posicions al mateix temps, tenint en compte que totes les lectures tenen una contradicció interna. En aquest sentit, les escletxes que trobem a Cap al cel obert, com les actituds d'Àngela i de Maria envers personatges que són víctimes del tràfic de dones, generen un interès de lectura de la novel.la basat en el fet que ambdues tenen una capacitat d'acció molt limitada per les seves relacions de parentiu, que les amortallen. En realitat, elles mateixes són víctimes d'aquest tràfic: sempre definides com a germanes, filles o mullers, sempre pendents de les decisions dels homes de la seva família que determinen el seu destí. Violeta i Felicitas els ofereixen un mirall de la seva situació, una imatge que nosaltres com a lectores i lectors podem relacionar. La imatge del mirall que Violeta i Felicitas retornen fa evident la incapacitat d'actuació d'Àngela i de Maria, víctimes també del tràfic de dones i de les relacions de parentiu. Lynne Pearce (1997) ha remarcat que llegir no és solament una cosa que nosaltres fem als textos, sinó també una cosa que els textos ens fan a nosaltres; la seva és una postura dialògica, de relació entre el text i la lectora. Des d'aquesta perspectiva, podem considerar Cap al cel obert com un text que ens permet estudiar el tràfic de dones en el segle XIX i els seus efectes en la construcció de les subjectivitats en femení. Així, doncs, la novel·la ens ofereix una visió de la història i un punt de vista que no s'havia explicat fins ara.

\section{La trama de Parker i el problema de la versemblança narrativa}

La crítica feminista Nancy Miller parteix de la formulació de Gérard Genette (1966) per destaca la importància dels conceptes de versemblança (vraisemblance, plausibility) i d'adequació (bienséance, propriety) proposats per aquest gran narratòleg francès. Perquè una novel-la sigui acceptada ha de tenir aquestes dues qualitats, que estan relacionades amb els prejudicis i les màximes del sistema de valors d'una societat. Entenem un personatge si podem relacionarlo amb una màxima de conducta aprovada i general; per tant, si no hi ha cap màxima per a un comportament determinat, es considera que tal comportament no és versemblant ni adequat. Genette basa la versemblança en un "acord tàcit" entre el text i el seu públic lector: el silenci implica plaer i significa conformitat amb la ideologia dominant. Allò que més ens interessa aquí és destacar la interpretació que en fa Miller (1988: 44): "To read women's literature is to see and hear repeatedly a chafing against 'the unsatisfactory reality' contained in the maxim". Tota la novel.la Cap al cel obert es pot entendre sota aquesta perspectiva. La història de Maria no troba cap final feliç en la trama principal i és només en l'epíleg prescindible on aconsegueix una vida al marge del final del llibre. L'artífex d'aquest possible final feliç al marge és David S. Parker, de nom 
real Tomeu Moner. No sabem realment què podem creure i què no de la seva biografia, ja que són moltes les històries que circulen al voltant del seu nom i a les quals accedim, sobretot, a partir del personatge d'Àngela amb les seves dues visites a la finca, si bé ella es mira Parker amb recel ja que havia sentit a dir que "vivia amb una guarda de concubines amb les quals tenia nombrosos fills, perquè la seva religió alcorànica li ho permetia" (Riera, 2000: 82). Àngela es relaxa quan beneeix la taula i es mostra disposada a idealitzar-lo, seduïda per l'excés del luxe, els criats blancs i rossos i l'estil neoclàssic de la finca. Tanmateix, en una visita per sorpresa, coneix Violeta i descobreix, d'aquesta manera, que Parker té esclaus blancs. ${ }^{5}$ De fet, ell mateix li ho explica sense embuts:

Violeta era, o és, tant de bo sigui viva, en efecte, una esclava, nascuda a la meva granja de Recife i criada allà fins als dotze anys, en què vaig fer que amb d'altres companyes escollides, vuit per ésser exactes, vingués a Cuba. Volia acabar-les d'anostrar personalment, donar el vistiplau a la seva educació com he fet des que vaig comprar el Morena Clara... Volia fruir de la contemplació dels cossos en l'hora fugissera de la seva transformació, el pas -afegí, malenconiós, en veu baixa- de la infantesa a l'adolescència tan breu, claror efímera, regal dels déus que encara permet oblidar la derrota.. plenitud mai més..., com a pètals caiguts sobre la memòria... (Riera, 2000: 153)

Aquest personatge demana una posició de lectura activa ja que no sabem fins a quin punt Àngela és un narrador fiable ni tampoc si les seves fonts ho són: ella s'enamorarà de Panxo Gómez precisament perquè és la persona que sap més coses de Parker. Serà aquest pretendent qui li explicarà que el nom real de Parker és Tomeu Moner i que és originari de Mallorca. Tanmateix, havia estat corsari i condecorat pels anglesos. D'altra banda, sembla que només Parker hagi sabut veure alguna cosa més darrere la superfície d’Àngela; li diu: "M’agraden les dones agosarades. Sempre vaig pensar que vostè era una rebel, un àngel rebel..." (Riera, 2000: 166). No sabem què ha ocorregut realment ni amb la seva sòcia Dorothy ni amb Violeta, ni quin ha estat el paper de Parker en la seva desaparició.

Ara bé, amb "l'epíleg prescindible" amb què acaba la novel.la, el personatge de Parker agafa tota una altra dimensió. Descobrim que gràcies a ell, Rodríguez de la Conca, el capità general, cau en desgràcia al govern de Madrid. També inicia una campanya per salvar Maria del garrot vil des d'Estats Units i així pot fugir amb globus: a més, s'haurien casat i ell hauria afillat el seu fill. És a dir, que un final feliç hauria estat possible. Això sí, és un final de romanç, fora de la trama principal de la novel.la. Creure'ns aquest final ens obliga a una actitud activa com a lectores i lectors: hem de netejar el personatge de Parker de prejudicis i veure'l

\footnotetext{
${ }^{5}$ Parker mateix explica a Àngela com es defineix : "No sóc traficant, sinó criador, criador de blanques i de blancs, especialitzat a millorar la nostra raça... (Riera, 2000: 154).
} 
sota aquesta nova llum. Aquí la ironia, una de les eines narratives indestriables de l'estil de Riera, ens pot ajudar. Si bé a l'epíleg Parker fa el paper d'heroi, aquest heroi no pot tenir un passat més brut ni un expedient més tacat.

\section{Al marge de la trama principal: la llegenda}

El cop d'efecte final, aconseguit amb "I un epíleg prescindible", recull el desig de Maria de perdurar en la memòria collectiva. Depèn de la versemblança de l'epíleg de l'autoritat que vulguem atorgar a la frase "pocs mesos després de la mort per garrot vil de Maria de Fortesa” (Riera, 2000: 347). Segons la narratòloga Susan Lanser (1992), l'autoritat discursiva, això és, la credibilitat intel-lectual, la validesa ideològica i el valor estètic atribuït a una obra, un autor, un narrador, un personatge o pràctica textual, es produeix d'una manera interactiva. De fet, Lanser considera que la veu narrativa pot ser un lloc de desafiament, de crisi i de contradicció; els textos que analitza tenen molts paral-lelismes amb Cap al cel obert, ja que construeixen veus narratives que volen inscriure's dins de la literatura i que reclamen una autoritat que no tenen: aquest seria el cas de l'epíleg i també el del romanç que canta el cec Raül. Sota aquesta perspectiva, interpretem l'epíleg com un espai narratiu fonamental ja que recull la necessitat de la comunitat narrativa de crear noves llegendes que recuperin l'experiència femenina i la converteixin en representable.

Maria ha pogut sobreviure només al marge de la trama principal; només amb la irrupció de la màgia ha pogut escriure una vida de llegenda: el seu fill, Josep Joaquim de Fortalesa i Fortesa, va acudir a Mallorca per trobar les petjades de la mare i en sentir un romanç se'l va aprendre de memòria. Segons aquest romanç, Maria hauria salvat la vida pujant a l'aerostàtic. Serà la néta de Maria qui descobrirà que el cos de l'àvia mai va ser lliurat a la família, amb la qual cosa "li semblà que aquest fet podia significar que, finalment, Maria no havia mort" (Riera, 2000: 351). La narració oral esdevé una prova versemblant per donar un altre final a la història: "prova que es salvà, fugint amb aerostàtic o de qualsevol altra manera, era el romanç. Qui podia saber si no ella tots aquells detalls de la seva vida. El compongué i l'envià a Raül” (Riera, 2000: 351). Per donar credibilitat a aquests fets, hem de tornar acudir a Nancy Miller: "The point is that the plots of women's literature are not about 'life' and solutions in any therapeutic sense, nor should they be. They are about the plots of literature itself, about the constrains the maxim places on rendering a female life in fiction" (Miller, 1988: 43). Efectivament, la ficció de la vida de Maria no té un final feliç versemblant a la trama principal: és en un "epíleg prescindible" on es pot jugar amb la possibilitat d'un final feliç, fora de les lleis de la mateixa trama i amb una dosi molt gran d'ironia.

En diferents moments de la novel.la, Maria té tant el desig com la premonició que viurà una llegenda, que romandrà en la memòria col-lectiva: "Havia somiat que cantava un romanç molt bell i molt trist en el qual ella sortia, 
però no podia recordar res més" (Riera, 2000: 60). El cec Raül apareix per primera vegada al capítol cinquè i Maria farà al·lusió a ell més endavant, quan ja a Cuba, a la finca La Deleitosa, escriurà a Àngela per confessar-li que no és Isabel. En parlar-li de la seves experiències d'escriptura es defineix "com a ajudant d'un poeta mancat d'inspiració - anotà- perquè li feu vergonya al.ludir al cec que cantava romanços pel carrer, perquè no s'atreví a reconèixer la seva escassa categoria" (Riera, 2000: 95). Tanmateix, la categoria d'aquest personatge i la seva concreció reben una altra valoració a l'epíleg. Com molt bé ha dit Lluïsa Julià (2009: 52-53): "Maria no hi juga cap paper, mor per la conveniència del poder dels altres". Aquest personatge femení no ha tingut cap oportunitat d'explicar-se ni ha pogut donar una dimensió èpica a la seva experiència, però la narració li dóna una oportunitat: la salva per la irrupció d'un element fantàstic, el globus aerostàtic. El fet que ella mateixa hagi explicat la seva salvació (el romanç que va enviar al cec Raül) trenca totalment el concepte de versemblança narrativa, que hem definit més amunt seguint Nancy Miller, però ha trobat un espai on poder viure lliure i feliç, totalment al marge de la trama principal, en un epíleg prescindible. Ha esdevingut una llegenda. Susan Winnett ha reflexionat sobre la importància de llegendes construïdes al marge de la trama principal com un espai únic on poden habitar les protagonistes. En les seves paraules:

La leyenda cuenta una historia que ha terminado. Su significado no ha sido establecido por su protagonista, sino por la comunidad que recuenta la historia, que ha pasado a ser la única medida de la importancia de la misma. La leyenda es posesión de una comunidad en la medida en que esa comunidad está poseída por una historia que, literalmente, ha sobrevivido a su protagonista. Ya no es por más tiempo la narración de un intento individual de autodeterminación, sino que la leyenda predetermina la manera en que cada persona de la comunidad narrativa otorga un significado a la trama de su propia vida. La leyenda, entonces, estructura la comunidad, por lo que determina el futuro de su propia recepción. (Winnett, 1999: 170)

La força de la llegenda és diferent de la força de la trama: l'impacte dels fets és més gran en la comunitat si es tracta d'una llegenda. És un clam que considera que la comunitat narrativa necessita noves llegendes per rescatar l'experiència femenina dels marges i reintegrar-la al lloc principal. Aquesta operació està molt d'acord amb la concepció de l'escriptura que té la mateixa Carme Riera, que ha definit l'acte d'escriure de la manera següent: "Això significa dir mentides a voler, transformar la realitat, manipular-la i, malgrat tot, gràcies a tot això, gràcies a la capacitat fabuladora, defensar allò per què la literatura també serveix: establir un compromís moral amb la llibertat, la tolerància i la dignitat humanes" (Riera, 2004: 227). 


\section{REFERÈNCIES BIBLIOGRÀFIQUES}

Bartrina, Francesca (2011), "Narratives de la identitat a Cap al cel obert (2000) de Carme Riera", Els subjectes de l'alteritat: estudis sobre la narrativa de Carme Riera, Pilar Arnau i Luisa Cotoner (eds.), Barcelona, Publicacions de l'Abadia de Montserrat: 59-74.

DuPlessis, Rachel Blau (1985), Writing Beyond the Ending: Narrative Strategies of Twentieth-Century Women Writers, Bloomington, University of Indiana Press.

Broch, Àlex (2004), "Cuba en la literatura contemporánea”, Cuadernos Hispanoamericanos, 648: 63-73.

Cotoner, Luisa (2005), "Carme Riera, sota el signe de Janus. Elogi de La meitat de l'ànima”, Carme Riera. II Premi de Narrativa M. Àngels Anglada, Figueres, Institut Ramon Muntaner: 16-35.

Cornejo Parriego, Rosalía (2011), "Por el cielo y más allá de Carme Riera: fluctuaciones y fijaciones sociales en un folletín colonialista", Cincinnati Romance Review, 30: 3-16.

Fuss, Diana (1999), En essència: feminisme, naturalesa i diferència, Eva Espasa (trad.), Vic: Eumo.

Genette, Gérard (1966), Figures II, París, Seuil.

Julià, Lluïsa (2009), Retrats: Carme Riera, Barcelona, Associació d'Escriptors en Llengua Catalana.

Miller, Nancy (1988), Subject to Change. Reading Feminist Writing, Nova York, Columbia University Press.

Lanser, Susan S. (1992), Fictions of Authority. Women Writers and Narrative Voice, Ithaca \& Londres: Cornell University Press.

Pearce, Lynne (1997), Feminism and the Politics of Reading, Londres, Arnold.

Pinyol, Rosa Maria (2000), "El folletín era el género idóneo para escribir sobre la Cuba del XIX", La Vanguardia, 22 de març.

Ramón, Emilio (2005), "La esclavitud del discurso y la liberación de la memoria en Por el cielo y más allá", Lectora. Revista de dones i textualitat, 11:215-233.

Riera, Carme (2000), Cap al cel obert, Barcelona, Destino.

-(2001) Por el cielo y más allá, Madrid, Alfaguara.

-(2004) "Carme Riera", (Des)aillats: Narrativa contemporània i insularitat a les Illes Balears, Margarida Pons i Catalina Sureda (eds.), Barcelona, Publicacions de l'Abadia de Montserrat.

Rubin, Gayle (1998), "El tráfico de mujeres: notas sobre la 'economía política' del sexo", Jessica McLauchlan i Mirko Lauer (trads.), ¿Qué son los estudios de mujeres? Marysa Navarro i Catharine R. Stimpson (eds.), Argentina, Fondo de Cultura Económica: 15-74. [1975] 
Valls, Fernando (2000), "Primera lectura de Cap al cel obert de Carme Riera", El mirall i la màscara. Vint-i-cinc anys de ficció narrativa en l'obra de Carme Riera, Luisa Cotoner (ed.), Barcelona, Destino: 301-314.

Winnett, Susan (1999), "Distinciones: mujeres, hombres, narrativa y principios de placer", Francesca Bartrina (trad.), Feminismos literarios, Neus Carbonell i Meri Torras (eds.), Madrid, Arco/Libros: 147-174.

\section{(c) (1) $(9)$}

